Journal of Engineering and Applied Sciences 15 (1): 153-158, 2020

ISSN: 1816-949X

(C) Medwell Journals, 2020

\title{
Managing Water Quality at Lake Chini using Sensors and Mobile App
}

\author{
Mohamad Shanudin Zakaria, Muhamad Shukri Ramli and Ahmad Tarmizi Abdul Ghani \\ Faculty of Information Science and Technology, Universiti Kebangsaan Malaysia, \\ 43600 Bangi, Selangor, Malaysia
}

\begin{abstract}
The usage of sensors to monitor water quality at Lake Chini started in 2010. Its purpose is to facilitate authorities in controlling the source of pollution and indirectly monitor and enforce the rules set out under the water enactment act. Water quality Index is used to measure cleanliness and the quality of water to sustain the rich and diverse biodiversity of flora and fauna. The telemetry system in operation since 2010 is adequate for such purpose. However, the rampant logging, mining and plantation activities in the last 5 years discharged waste such as sediment, fertilizer and toxic into the lake and threaten the lake biodiversity. The sensors operated within a polluted environment. The big flood of 2014/2015 further decimated all telemetry stations and rendered them inoperable. We are faced with the challenge of rebuilding the collapsed infrastructure and resuming the measurement of water quality parameters. The new telemetry system incorporated two new features to ensure accessibility: A dashboard and early warning system and moving data and application into the cloud. A smartphone app was developed to facilitate the acquire readings from sensor and facilitate the sharing of these data.
\end{abstract}

Key words: Lake Chini, water quality index, sensors, telemetry systems, mobile apps

\section{INTRODUCTION}

Located $300 \mathrm{~km}$ Northeast from the capital Kuala Lumpur, Lake Chini is the second largest natural lake in Malaysia. It extends between the coordinates of $3^{\circ} 24^{\prime} 40$ “N to $3^{\circ} 26^{\prime} 42^{\prime \prime} \mathrm{N}$ and $102^{\circ} 52^{\prime} 18^{\prime \prime} \mathrm{E}$ to $102^{\circ} 55^{\prime} 54^{\prime \prime} \mathrm{E}$ formed from a combination of 12 open bodies of water known as 'Laut' or 'sea' by the native Jakun tribe. The 200 ha lake is surrounded by 5000 ha of swamp forests and freshwater swamps forming an area known as Tasik Chini forest reserves (Toriman et al., 2010).

In 2009, UNESCO accorded Biosphere Reserve Status on Lake Chini due to its rich and diverse biodiversity of flora and fauna, many endemic or unique to Lake Chini. About 800 indigenous people from Jakun tribe made their homes in the vicinity of the lake. It is also home to 87 species of freshwater fish, 189 species of birds, 51 low forest species, 15 freshwater swamp forest species and 25 aquatic plant (NST, 2019). The natural environment in Lake Chini that includes the flora and fauna, rivers, swamps, lowland and hill forests as well as the indigenous people form a unique ecosystem. This ecosystem depends on the lake for their survival and water supply.

In the present study, we present our work in monitoring water quality of the lake. We also presented a new architecture of our telemetry stations after the big flood of 2014/2015 decimated all our stations and components.

\section{MATERIALS AND METHODS}

Ensuring healthy water quality here is vital for the survival of the ecosystem. In this study, we examined the role of Malaysian Department of Environment (DOE) and Lake Chini Research Center (LCRC) in monitoring water quality of the lake using samplings and telemetry station. We present our work on restoring the architecture of the telemetry systems and resuming the process of acquiring readings from sensors.

To ensure the quality of water at Lake Chini meets the established standards, the DOE has been entrusted by the government to consolidate surveillance and rehabilitation programs at Lake Chini. These involved the activities of collecting, archiving and distributing water quality data, since, March 1978. In addition, DOE also plays a role in determining water quality status and water quality changes caused by development activities as well as identifying the causes and levels of pollution. In carrying out the tasks and roles, routine in-situ surveillance at sampling stations and laboratory analysis were carried out periodically. A total of 23 telemetry stations have been built to collect parameters from sensors which will be used to calculate water quality index and classify the index.

In addition to DOE in 2010, LCRC of Universiti Kebangsaan Malaysia built seven telemetry stations to measure and record water quality parameters at seven different rivers that formed part of inflow and outflow

Corresponding Author: Mohamad Shanudin Zakaria, Faculty of Information Science and Technology, Universiti Kebangsaan Malaysia, 43600 Bangi, Selangor, Malaysia 


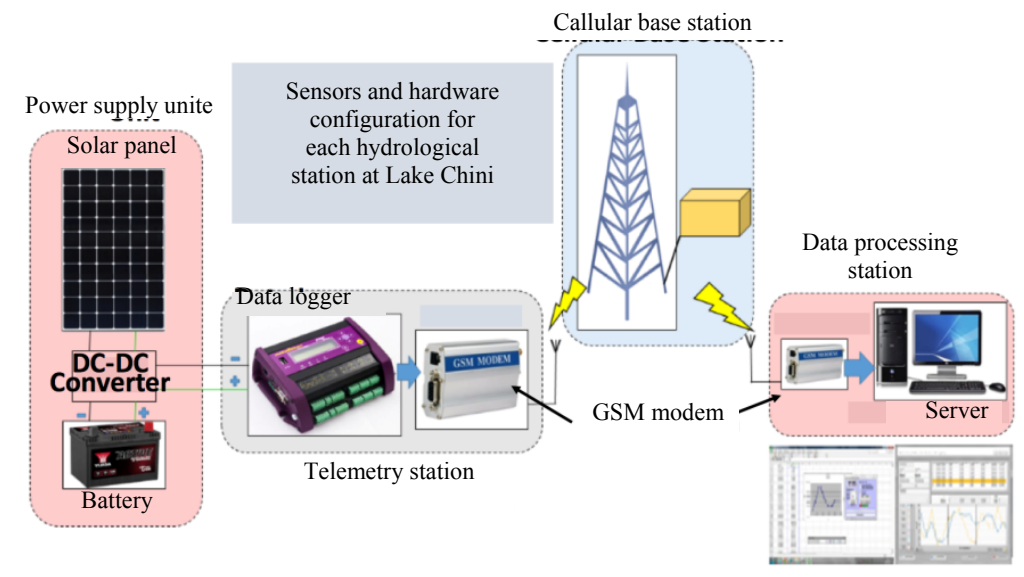

Fig. 1: Architecture of original telemetry station at Lake Chini

streams into the lake. Figure 1 shows the architecture of the telemetry station of LCRC. Every sampling station consists of a tower block that houses solar cell and battery for power supply, a data logger to record readings from sensors, a GSM modem and antenna to transmit the data from data logger to a server at LCRC. The measurement taken are temperature $\left({ }^{\circ} \mathrm{C}\right)$, conductivity $\left(\mu \mathrm{S} \mathrm{cm}^{-1}\right)$, total dissolved solid ( $\left.\mathrm{mg} \mathrm{L}^{-1}\right), \mathrm{pH}$ (unit), turbidity (NTU) and optical dissolved oxygen $\left(\mathrm{mg} \mathrm{L}^{-1}\right)$. Details of the parameters and methods on water anaylysis can be found in Shuhaimi-Othman et al. (2007).

In addition to water quality, every station was also equipped with sensors for hydrology and climatology. These sensors share the same data logger and GSM modem.

Water quality index and classifications: In Malaysia, two measurements have been adopted for water quality to determine the status of pollution and water usage: The Water Quality Index (WQI) introduced by DOE and the Interim National Water Quality Standard for Malaysia (INWQS) developed by National Hydraulic Research Institute of Malaysia (NAHRIM).

The water quality index and classification of water quality standard for river and lake needs to be determined to further facilitate the authorities in controlling the source of pollution and indirectly monitor and enforce the rules set out under the water enactment act. The WQI is used to measure cleanliness and the quality of water supply for domestic usage, aquaculture and irrigation. It provides a comprehensive picture of the water quality status based on soil use factors, types and sources of pollution and pollution levels. This index also works to identify the main types of water pollution by referring to specific stations based on the percentage of impurities content to be analyzed.
Table 1: Water quality standard for rivers in malaysia

\begin{tabular}{|c|c|}
\hline Class & Definition \\
\hline \multirow[t]{3}{*}{ Class I } & Conservation of natural environment \\
\hline & Water supply I-Practically no treatment necessary \\
\hline & Fishery I-Very sensitive aquatic species \\
\hline Class II A & Water supply II-Conventional treatment \\
\hline \multirow[t]{2}{*}{ Class II B } & Fishery II-Sensitive aquatic species \\
\hline & Recreational use body contact \\
\hline \multirow[t]{2}{*}{ Class III } & Water Supply III-Extensive treatment required \\
\hline & $\begin{array}{l}\text { Fishery III-Common of economic value and tolerant } \\
\text { species; livestock drinking }\end{array}$ \\
\hline Class IV & Irrigation \\
\hline Class V & None of the above \\
\hline
\end{tabular}

Table 2: Water quality standard for lakes in Malaysia

\begin{tabular}{ll}
\hline Class & Definition \\
\hline Class A & Primary body contact \\
Class B & Secondary body contact \\
Class C & Protection of ecosystem \\
Class D & Irrigation and general purposes \\
\hline
\end{tabular}

The value of WQI is obtained from the combined value of the 6 main parameters of water quality namely $\mathrm{pH}$, Dissolved Oxygen (DO), Biochemical Oxygen Demand (BOD5), Chemical Oxygen Demand (COD), Total Suspended Solid (TSS) and Ammonia nitrogen (NH3-N). The Interim National Water Quality Standard for Malaysia (INWQS) is based on the classification for the National Guidelines for the Quality of Raw Drinkwater.

Since, Lake Chini Reserve consists of a lake and a few rivers, two classifications of water quality standards are used at Lake Chini: water quality standard for rivers and water quality standard for lakes. The classification for rivers and lake are shown in Table 1 and 2, respectively. Water quality data by DOE were then stored in National Lake Malaysia (MyLake), a concentric database platform that stores data on lakes in Malaysia, developed by NAHRIM. LCRC kept their data at their own server. 
Need for revamp: The realtime updating into a centralized database has been an invaluable task. However, the big flood that began in late December, 2014 has totally decimated the telemetry stations and its components (Akasah and Doraisamy, 2015).

Floods are considered an annual natural disaster in the East Coast of Malaysia. However, the record-setting flood of 2014 was summed up by Baharuddin et al. (2014) as "the most significant and largest recorded flood in the history of Kelantan. It was considered to be a 'tsunami-like disaster' in which 202,000 victims were displaced."

The event demonstrates that the IT infrastructure at Lake Chini is unprepared for any eventuality. Risk Management was never carried out by both DOE and LCRC prior to the disaster. Jamali et al. (2018) carried out an IT Risk Management for the LCRC as a consequence of the flood. She observed that LCRC needs to promote some aspects of IT risk management policies such as developing a special risk management system or a special model for risk registration and data storage.

The big flood completely destroyed the IT infrastructure. Some of the stations were submerged and unreachable for more than a week. Due to the flood, devices vital to our sampling such as data loggers, power supplies and routers were unserviceable. Water quality sensors were not affected since they were designed to be submerged in water. However, due to the absence of supporting devices and power supply, vital data for the next few months were not logged in the data logger and not transmitted to the server by GSM modem.

Challenge: The LCRC were faced with two challenges: 1 Rebuilding of the collapsed infrastructure and 2 Resuming the measurement of water quality parameters. The former involved bringing in a significant amount of funding and the process will take a few years to achieve. Whilst efforts on restoring every sampling station were in progress, measurement of water quality parameters must resumed.

\section{RESULTS AND DISCUSSION}

Rebuilding the collapsed infrastructure: Since, its inception, network coverage was a dismal $2 \mathrm{G}$. There were little incentives for telco to upgrade to $3 \mathrm{G}$ or $4 \mathrm{G}$ since the area is unpopulated. Transmitting data using $2 \mathrm{G}$ is expensive since, the charging structure is based on per connection rather than volume. The exorbitant charge prevent LCRC from having a true realtime monitoring. Readings from sensor were taken in a certain time frame and collected in the logger data before being sent to the server system. In our case, data from sensors were logged every 15 minutes, stored in the data logger and transmitted to the server once every $8 \mathrm{~h}$. This process was chosen purely for economic reason.

Since, 2010, the system served its purpose. However, the economic activities (logging, mining and plantations) around the lake present new challenge. In particular, wastes from these activities such as sediment, fertilizer and toxic that flow into the lake gave a lasting effect to the flora and fauna and threaten the lake biodiversity.

In 2018, LCRC secured funding from East Coast Economic Region Development Council (ECERDC) to refurbish and restore all sampling stations using the latest technology and know-how. Revamping current stations is not a matter of replacing all available devices and tools. LCRC needs a network of systems capable of providing accurate and speedy information to enable the environment to be monitored and able to benefit users of local communities and relevant agncies. The latest and real-time data needs will assist stakeholders in preserving and conserving the river environment in Lake Chini in particular and the lake catchment area in general. This environmental information also helps researchers and government agencies in assessing environmental conditions as well as providing early steps to relevant agencies to take appropriate action to help conserve and preserve the environment of Lake Chini.

These new necessities need to be incorporated within the new telemetry system. A few adjustments to the present telemetry system need to be made. First, a dashboard and early warning system is needed. Dashboard should be able to:

- Display raw data and the water quality index periodically

- Visualize parameters taken from the sensors

- Display interactive maps showing the location of all seven sampling stations and the parameters

- Access data anytime and anywhere using various devices

A flexible early warning system allows LCRC to set a threshold for certain parameters and warn the communities and agencies for further action if sensor readings are beyond the threshold range. This is necessary for LCRC to detect any event that demand immediate mitigation such as flood and pollution.

The second new requirement is for LCRC to disseminate their findings to interested researchers, communities and agencies. It is essential for the recipients to transform the digital footprint into something meaningful and practical. In order to provide this initiative, current and future data must be made accessible. A physical server current being deployed is not particularly apt for such purpose. 


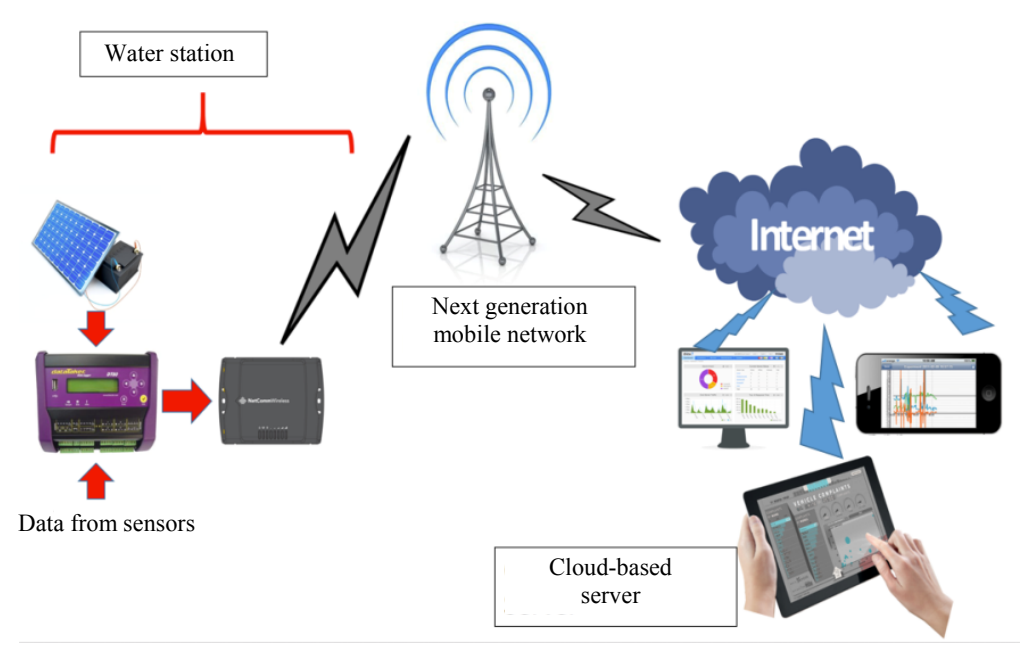

Fig. 2: New architecture for telemetry station

Current and future data must be stored in a cloud. Moving data into public cloud will ensure public accessibility as well as discharge LCRC from daily operations of maintaining a physical server such as security and backup. The cloud will also be hosting the dashboard and early warning system. This public repository will make it easier for realtime data from data logger to be accessed by the dashboard and early warning system as well as in-situ calculation of WQI.

Figure 2 shows the architecture of new sampling station. A solar panel and battery will provide power supply to data logger which will accept readings from water quality, hydrology and climatology sensors. The readings will be pushed to a router for data transfer to the cloud via a mobile network. Each monitoring station is equipped with a mobile/wireless network technology that has high reliability with no interruptions and security issues. All monitoring stations form a separate network infrastructure and operate on the data plan allocated to it. Data transfer will be regular and continuous. The rebuilding is ongoing and scheduled to be completed in September, 2019.

Resumption of the measurement of water quality parameters: The damage to sampling stations due to the great flood has paralyzed the data collection activity. In early 2017, both DOE and LCRC recommence data collection, albeit manually. Research assistants were deployed to physically download whatever data remaining in the data loggers into a flash drive and manually upload them into a server. This costly activity demands time and resources. For stations where equipments were totally unusable, parameters were taken manually. Data were uploaded to the server either in Excel or CSV form.
The manual process brought a number of problems. The most significant problem is the difficulty in sharing data among researchers. We opted to develop a smartphone application (Lake Chini System or STC) specifically for such purpose. The apps primary focus is sharing data on the monitoring and preservation of Lake Chini water quality. Officers from DOE and LCRC were consulted to solicit their view on moving from existing server-based monitoring and conservation system to a smartphone-based system. Their views were also sought on retaining existing work procedures features and functions to be incorporated into the mobile app. In short, the design focuses around three components as depicted in Fig. 3. The three components are:

Data collection: Once the data were collected and collated by the researchers, this component facilitates the uploading of raw data in Excel or CSV form into the database. All file transaction records containing data types, time, size and status information will be recorded for audit trails if required.

Data processing: The temporal data collected will be used to determine WQI and classification of water quality standard for rivers and Lake Chini at any point in time.

Data presentation: The main purpose of the STC is to enable DOE and LCRC to monitor water quality at Lake Chini with ease and to disseminate the outcome to researchers, communities and agencies. A dashboard was developed to display brief information required by them in the form of tables, statistics, charts and graphs. The content can be downloaded by users in Excel, PDF or $\mathrm{CSV}$ form for further analysis. A search function is also provided for user to request archived data in the database 

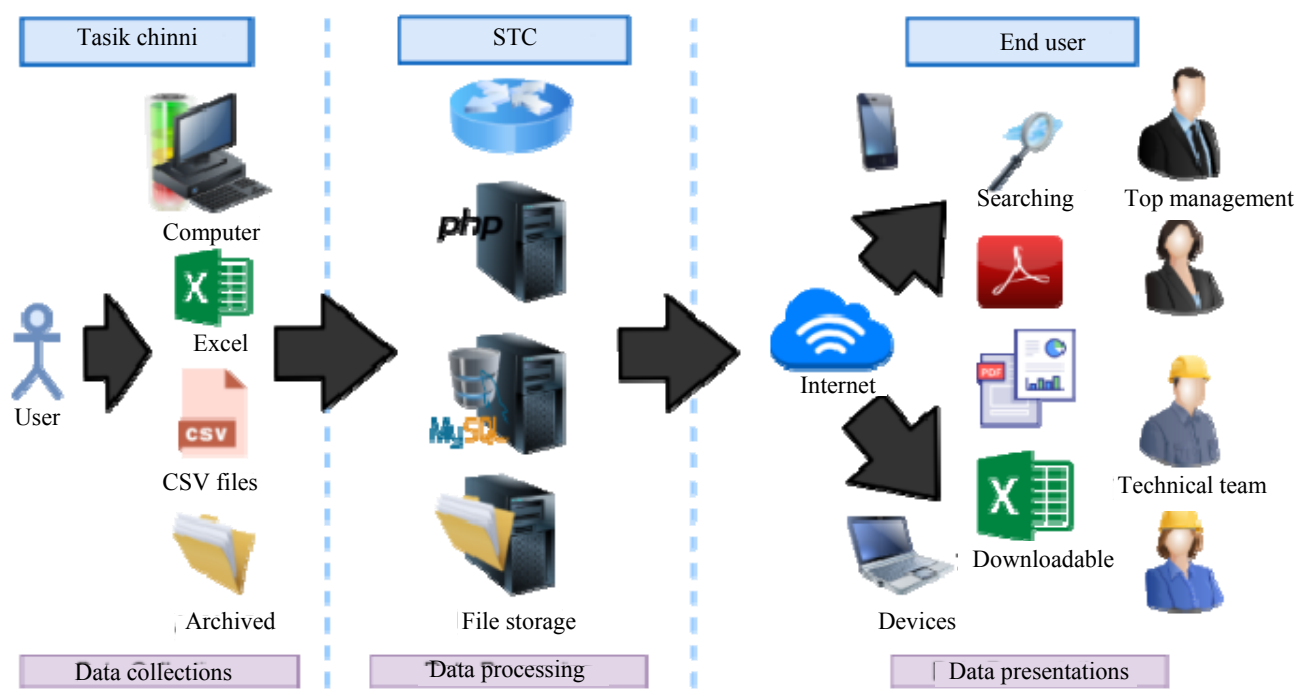

Fig. 3: Design of mobile app STC

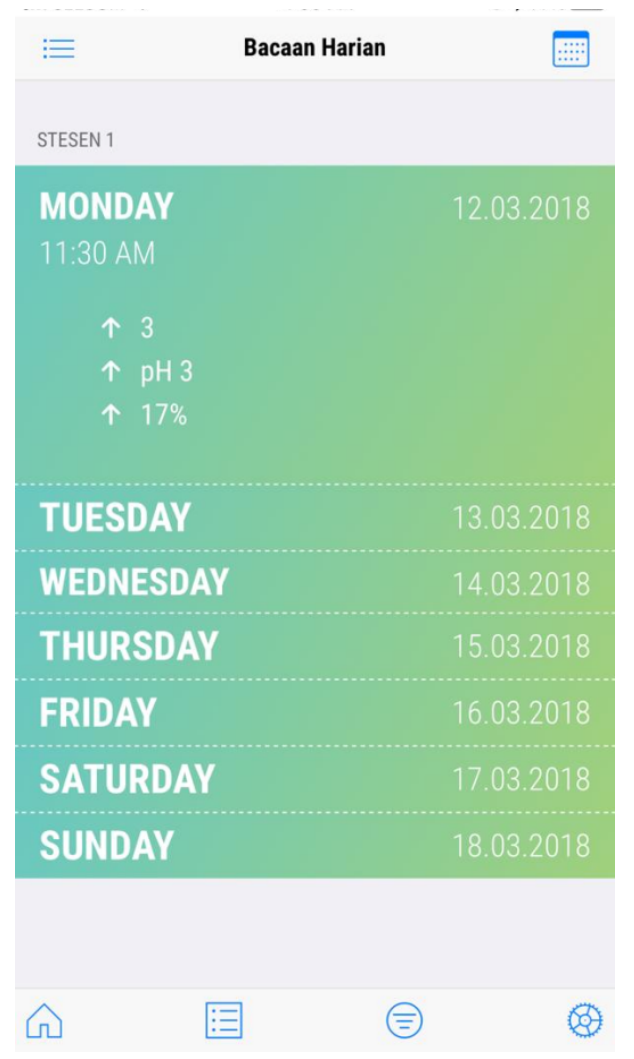

Fig. 4: Data for station 1

The data for any station can be obtained at any time and any date (Fig. 4) as well as the calculated water quality index for any or all stations (Fig. 5).

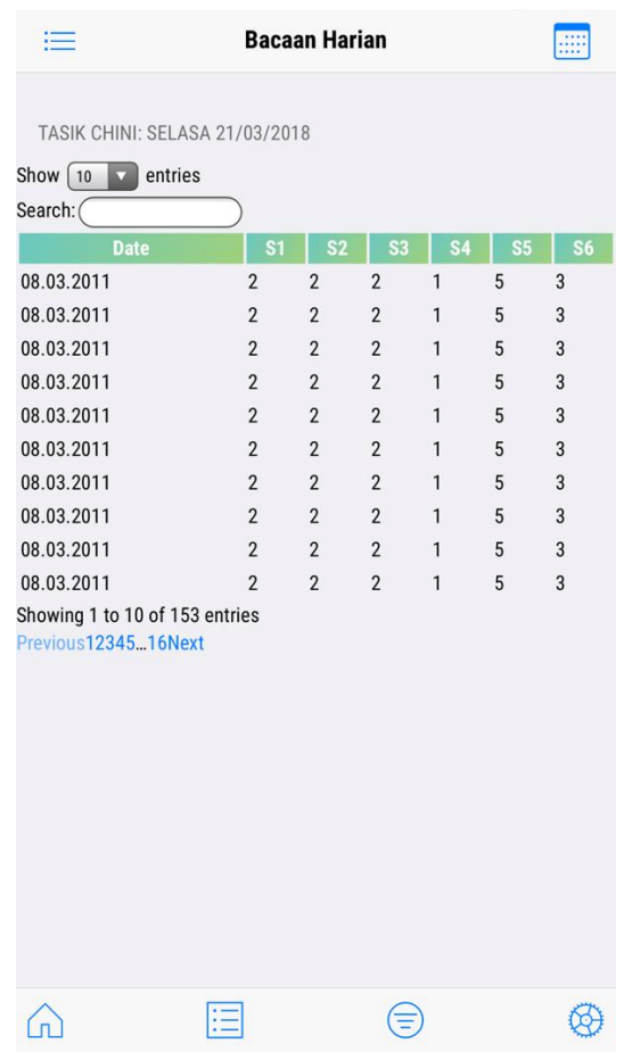

Fig. 5: Daily WQI

\section{CONCLUSION}

This study focused on the restoring the telemetry stations at Lake Chini as well as the resumption of 
processes and activities to acquire valuable data from sensors which were halted due to the damage caused by the great flood of 2014/2015. Despite the telemetry stations still under construction, we are able to obtain vital data and share through a mobile app.

\section{REFERENCES}

Akasah, Z.A. and S.V. Doraisamy, 2015. 2014 Malaysia flood: Impacts and factors contributing towards the restoration of damages. J. Sci. Res. Dev., 2: 53-59.

Baharuddin, K.A., S.F.A. Wahab, N.H.N.A.B. Rahman, N.A.N. Mohamad and T.H.T. Kamauzaman et al., 2015. The record-setting flood of 2014 in Kelantan: Challenges and recommendations from an emergency medicine perspective and why the medical campus stood dry. Malaysian J. Med. Sci., 22: 1-7.
Jamali, S.N., M.S. Zakaria and S.N. Jamali, 2018. A risk management approach to the development of an early warning system: A case for Tasik Chini. Asia Pac. J. Inf. Technol. Multimedia, 7: $115-130$.

NST., 2019. NST leader: Act now to save Tasik Chini. New Straits Times, Kuala Lumpur, Malaysia. https://www.nst.com.my/opinion/leaders/2019/02/4 62821/nst-leader-act-now-save-tasik-chini

Shuhaimi-Othman, M., E.C. Lim and I. Mushrifah, 2007. Water quality changes in Chini Lake, Pahang, West Malaysia. Environ. Monit. Assess., 131: 279-292.

Toriman, M.E., M. Idris and N.R. Jamil, 2010. Monitoring spatial variability of lowland dipterocarp forest in Lake Chini catchment, Malaysia. World Applied Sci. J., 8: 54-60. 